\title{
Changes in travel behavior of commuters between 1970 and 2000
}

\section{Journal Article}

\section{Author(s):}

Froehlich, Phillip

Publication date:

2008

Permanent link:

https://doi.org/10.3929/ethz-b-000159174

Rights / license:

In Copyright - Non-Commercial Use Permitted

Originally published in:

Transportation Research Record 2082(1), https://doi.org/10.3141/2082-05 
TRB 08-2363

\section{TRAVEL BEHAVIOR CHANGES OF COMMUTERS}

\section{BETWEEN 1970 AND 2000}

Philipp FROEHLICH

Institute for Transport Planning and Systems (IVT)

ETH Zurich

Wolfgang-Pauli-Strasse 15

CH-8093 Zurich

Switzerland

Phone: +41-44-633 3196

Fax: +41-44-633 1057

Email: froehlich@ivt.baug.ethz.ch

Text: $\quad 4578$ words

Figures: $\quad 4$ (=1000 words)

Tables: $\quad 5(=1250$ words $)$

Total: $\quad 6828$ words 
Submitted: $1^{\text {st }}$ April 2008

\begin{abstract}
The paper describes research on estimating sequential discrete choice models for mode choice, destination choice and interzonal trip generation of commuters from 1970 to 2000 in Switzerland. The research is based on detailed data sets that track the development of the private and public transport system and the socioeconomic variables at the level of local municipalities. Major changes in mode choice were identified via the estimated parameters of travel cost, quantity adjusted car ownership cost and car ownership per licensed driver. The results of the interzonal trip generation show that demand reacts with positive elasticity to accessibility, but also that the accessibility of a zone becomes less important for the generation of interzonal work trips over time.
\end{abstract}




\section{INTRODUCTION}

Transport infrastructure projects are characterized by large investments and can over time change travel behavior and land use patterns. Modeling the interaction between infrastructure, land use and travel behavior is an especially interesting, challenging and current topic in transport planning research. Beginning in the 1990s, several researchers began applying time series techniques to examine these interactions, see for example (1) and (2).

A review of this literature (3) shows consistent findings for several different methodologies; in all cases the private transport (PrT) demand (measured in vehicle miles travelled, VMT) shows positive elasticity with respect to PrT infrastructure supply changes (measured in lane miles, LM). Published results show an elasticity of daily vehicle mileage with respect to lane miles of $0.2-0.3$ in the short run and $0.6-0.8$, in the long run. Other variables considered in different research projects included: population (with a strong positive elasticity value of PrT demand in the range of 0.4 to 0.7 ), income (with a positive elasticity value of PrT demand in the range of 0.1 to 0.4 ) and fuel price (with a negative elasticity value of PrT demand in the range of -0.05 to -0.2 ).

In almost all these time series studies the availability of accurate and valid data is a serious problem; therefore analyses are often carried out with highly aggregated datasets. In contrast, this study uses aggregate commuter data sets from the Swiss census for the years 1970, 1980, 1990 and 2000, but for the fine detail of 2900 Swiss municipalities. These commuter data were linked to municipal-level socio-demographic and transport supply data to estimate sequential discrete choice models for mode, destination and interzonal trip generation over the study time period. The project's main focus was to determine how commuter travel behavior has changed over the last 30 years.

The paper is organized as follows: Chapter 2 reviews the methodology used and presents the utility function used for the choice models. Chapter 3 describes and analyzes the data used in the study. In Chapter 4 the results are presented and the model results are interpreted. Finally, in Chapter 5 the study results are put into a broader context.

\section{METHODOLOGY}

Discrete choice models and, particularly multinomial logit models (MNL), have been used in transport planning for many years. The basic concepts are described in, among others, (4).

In MNL models, parameters $(\beta)$ are estimated for each alternative $i$ with the levels of attributes $\mathrm{x}$ to maximize the utility $(\mathrm{U})$ of a decision-maker and can be formulated as:

$\mathrm{U}_{\mathrm{i}}=\mathrm{V}_{\mathrm{i}}+\varepsilon_{\mathrm{i}}=\beta_{\mathrm{i}}^{\prime} \mathrm{x}_{\mathrm{i}}^{\prime}+\varepsilon_{\mathrm{i}}$

Where $V_{i}$ is the observed utility term and $\varepsilon_{i}$ is the unobserved utility term. 
Figure 1 presents an overview of the model structure used here. The sequential hierarchical structure starts by calculating an expected maximum utility (EMU) using MNL on the mode choice process. The expected maximum utility for the MNL is formulated as (with as scale factor, which is normally set to one):

$$
\mathrm{EMU}=\frac{1}{-} \log _{\mathrm{i}} \exp \left(\mathrm{V}_{\mathrm{i}}\right)
$$

The expected maximum utility is then used in the utility function of the MNL model where it is used to estimate destination choice. The same process is followed to estimate a Probit model of the share of outcommuters. A quite similar approach was used by (5) to estimate the impact of a new high speed train in Japan.

The mode choice utility functions for private transport (PrT) and public transport (PuT) are formulated as:

$$
\begin{aligned}
& V_{\mathrm{PrT}}=\beta_{\mathrm{PrT} \mathrm{tt}} * \text { PrT travel time }+\beta_{\mathrm{tc}} * \text { PrT travel cost } \\
& +\beta_{\text {car }} * \text { car by licenceholder }+\beta_{\mathrm{inc}} * \ln (\text { income }) \\
& +\beta_{\mathrm{qacoc}} * \text { quality adjusted car ownership cost } \\
& +\beta_{11} * \text { SRT } 11+\beta_{12} * \text { SRT } 12+\beta_{13} * \text { SRT } 13 \\
& +\beta_{14} * \text { SRT } 14+\beta_{21} * \text { SRT } 21+\beta_{22} * \text { SRT } 22 \\
& +\beta_{23} * \text { SRT } 23+\beta_{24} * \text { SRT } 24+\beta_{31} * \text { SRT } 31 \\
& +\beta_{32} * \text { SRT } 32+\beta_{33} * \text { SRT } 33+\beta_{34} * \text { SRT } 34 \\
& +\beta_{41} * \text { SRT } 41+\beta_{42} * \text { SRT } 42+\beta_{43} * \text { SRT } 43 \\
& +\beta_{44} * \text { SRT } 44 \\
& V_{\mathrm{PuT}}=\beta_{\text {PuT tt }} * \text { PuT travel time }+\beta_{\mathrm{tc}} * \text { PuT travel cost } \\
& +\beta_{\mathrm{T}} * \text { number of transfers }+\beta_{\mathrm{HW}} * \text { headway }
\end{aligned}
$$

The spatial relation types (SRT) were effect coded. Spatial relation types describe the type of municipality at the origin and destination, e.g. from suburbs to major city (with $1=$ major city; 2 = suburban; 3 = small freestanding city; 4 = rural).

The MNL-models (mode and destination choice) were estimated using the software package LIMDEP-NLOGIT (6). The observed choice data (inter-zonal work trips) were used as frequencies in the model.

For the destination choice model, the set of destinations was generated by including all observed destinations from an origin until the number reached 100 (the maximum number of alternatives that can be evaluated in the software package LIMDEP-NLOGIT). If more than 100 destinations were observed from a single origin, then 100 destinations were randomly selected for use in the model.

The attraction variables, number of employees in the second sector (industry) and third sector (service) are used in logarithmic form, because of their declining marginal utility. The 
expected maximum utility (EMU) from the mode choice model are already in logarithmic form and therefore do not need to be transformed.

$\mathrm{V}_{1}=\beta_{\mathrm{EMU}} * \mathrm{EMU}_{1}+\beta_{\mathrm{E} 2 \mathrm{~S}} * \log (\text { Employees } 2 \text { nd Sector })_{1}+\beta_{\mathrm{E} 3 \mathrm{~S}} * \log (\text { Employees 3rd Sector })_{1}$

$\mathrm{V}_{2}=\beta_{\mathrm{EMU}} * \mathrm{EMU}_{2}+\beta_{\mathrm{E} 2 \mathrm{~S}} * \log (\text { Employees } 2 \text { nd Sector })_{2}+\beta_{\mathrm{E} 3 \mathrm{~S}} * \log (\text { Employees 3rd Sector })_{2}$

$\mathrm{V}_{100}=\beta_{\mathrm{EMU}} * \mathrm{EMU}_{100}+\beta_{\mathrm{E} 2 \mathrm{~S}} * \log (\text { Employees } 2 \text { nd Sector })_{100}+\beta_{\mathrm{E} 3 \mathrm{~S}} * \log (\text { Employees } 3 \text { rd Sector })_{100}$

The interzonal trip model analyses how the different attributes affect the number of work trips leaving the origin zone (interzonal trips) as observed frequency of the total work trips. The interzonal trip generation was estimated as a Probit model with an alternative specific constant (ASC) and effect coded location types (LT) using the software SPSS.

$\mathrm{V}=\mathrm{ASC}+\beta_{\mathrm{EMU}} *$ EMU-Destination Choice $+\beta_{\mathrm{E} 2 \mathrm{~S} / \mathrm{ap}} *$ (Employees 2nd Sector/active population)

$+\beta_{\mathrm{E} 3 \mathrm{~S} / \mathrm{ap}} *$ (Employees 3nd Sector/active population)

$+\beta_{\text {Obl_Edu }} *$ Share with obligatory education $+\beta_{\text {HSD }} *$ Share with high school diploma

$+\beta_{\mathrm{Uni}} *$ Share with university education $+\beta_{\mathrm{Women}} *$ Share of woman of active pop

$+\beta_{\text {Income }} * \log ($ Income $)+\beta_{\mathrm{LT} 1} *$ Location Type $1+\ldots+\beta_{\mathrm{LT} 13} *$ Location Type 13

The elasticity values derived from the mode choice model show the impact of the change of one variable on another variable, for example, the relative change in market share based on a relative change in price. Direct elasticity measures the relative change (in percent) of mode choice probability for a given alternative (in this case public transport and private transport) in relation to the relative change in one attribute of the same alternative. The cross elasticity measures the relative change (in percent) of the mode choice probability for a given alternative in relation to the relative change in one attribute of the competing alternative.

The elasticity calculation was computed using the Probability Weighted Sample Enumeration (PWSE) (4). Using this method the aggregated elasticity (E) is calculated as follows:

$$
E_{x_{i k}}^{\bar{P}_{i}}={ }_{q=1}^{Q} \hat{P}_{i q} E_{x_{i k q}}^{P_{i q}} /{ }_{q=1}^{Q} \hat{P}_{i q}
$$

with $\bar{P}_{i}$ for the aggregated choice probability of alternative $\mathrm{i}$ and

$$
\hat{P}_{i q} \text { for the estimated choice probability of alternative i by individual } \mathrm{q} \text {. }
$$

The PWSE method is recommended for calculating elasticity values over the average and the naïve pooling methods, because the latter methods tend to overestimate the elasticity values.

\section{DATA}


The availability of accurate and consistent data is an essential and crucial ingredient of all statistical research and is especially true for analyses considering a long time periods. In this research different transport networks were constructed for private transport (PrT) and public transport (PuT) for each time horizon (2000, 1990, 1980 and 1970). These models were used to obtain appropriate impedance values (e.g., PrT travel time, number of transfers, PrT travel cost, etc.) for PrT and PuT between all 2,900 municipalities in Switzerland. This work is described in (7).

For this study, demand data was obtained from the commuter survey conducted within the Swiss national census. This is a very valuable dataset as it includes all work trips made by the entire Swiss workforce (defined as working over 6 hours per week) by mode. Table 1 presents an overview of the inter-zonal work trips over the 30-year study period. As shown, the number of inter zone trips increases over time and the pattern of trips is becoming more dispersed.

The cumulative share of the demand weighted travel speed for public and private transport modes over the study period is shown in . For private transport the median speed increases from 30 to $48 \mathrm{~km} / \mathrm{h}$. This clearly shows the impact of building major motorways in the 1970s. The travel speed in public transport increased less in absolute terms, from $15 \mathrm{~km} / \mathrm{h}$ to 22 $\mathrm{km} / \mathrm{h}$. This reflects the fact that during the 1970s the public transport system was only slightly improved, however more significant improvements followed in the 1980s and 1990s.

As part of the research, the income per municipality was calculated using data from tax statistics. Unfortunately, the income data is not consistent, because the minimum income needed to pay taxes did not increase significantly during the time period, and therefore the data has a downside bias in later years.

Another inconsistency occurred in the automobile registration data; during the 1970s the method of measuring registrations changed and therefore the 1970 data is not compatible with data from the following years. Several validation procedures were applied and as a result data from several municipalities was omitted. Finally, the number of cars per licence holder per municipality was obtained using information from cohort analysis of licence holders by gender and age group over time (8) and the age distribution by gender in every municipality.

The cost functions for public transport and private transport were calculated using the price structure for 2000 and the transport cost index (9) over time. The structure of public transport pricing changed over time (more annual tickets and fewer single point to point tickets were sold), but unfortunately there was no way to follow these changes precisely. The private transport cost function includes fuel cost and the cost for tire wear. The quality adjusted automobile ownership cost was taken from (10), where a separation of quality and price changes was estimated with the application of hedonic models. The reported price index from the work of (10) considers not only the price changes for passenger cars but also the increasing quality over time.

The number of employees in the second sector (industry) and third sector (service), the education level of the inhabitants, the number of employed women and the number of economically active population data were all obtained from census data for the appropriate year. 


\section{RESULTS}

First, the mode specific parameters will be discussed. Second, the estimated spatial relation type specific parameters will be interpreted. Third, the elasticities and values of travel time savings obtained in the research will be discussed. Finally, the results for destination and interzonal trip generation models are presented and discussed.

The results of the mode choice models for 1970 to 2000 are shown in Table 2. All the estimated parameters are significant and carry the expected sign.

All four mode-related parameters in the public transport utility function i.e. travel time, travel cost, number of transfers and headway, carry a negative sign, implying that they have a negative influence on public transport utility. Parameters with a possible positive sign, such as the ownership of annual tickets, could not be estimated due to the lack of data.

As can be seen, the values of the public transport travel time parameter fluctuates around -0.5 over the study period; this shows that employees are in no greater hurry to get to work today than they were 30 years ago. Another interpretation of this result is that the marginal utility of public transport travel time has remained relatively constant over the observed time period. No trend can be deducted from the parameters for headway and number of transfers.

Both the private and public transport utility functions contain the same travel cost parameter. This is based on the assumption that private and public transport users make decisions about money in the same way. The cost parameter increased continuously from -0.17 in 1970 to -0.08 in 1980 and to -0.04 in 1990; after 1990 it stayed constant. The weight of travel cost in the utility function decreases significantly over time.

The parameter for private transport travel time falls from -1.64 (1970) to -1.80 (1980) before rising to -1.35 (1990) and then falling again to -1.58 in 2000. These results are consistent with those for public transport, namely that employees are in no greater hurry to get to work today than they were in the 1970s.

The estimated parameters for car ownership per licensed driver double over the time period. It starts at 1.68 (1970), rising to 1.728 (1980), 2.411 (1990) and to 2.87 (2000), which shows that the marginal utility of car ownership in mode choice increased significantly over the last 30 years. As the car for every licence holder becomes normal, it is generally used for commuting.

The estimated parameters for average income on private transport are somewhat surprising. In 1970 and 1980 average income had a positive impact, while in 1990 and 2000 it had a negative impact, when for the quality adjusted car ownership cost is controlled for. This is surprising since many other studies have shown that income had a positive influence on the choice probability of private transport. However, most of these other studies were conducted with stated preference (SP) data and there income data per person can be used.

Another reason for the difference could be problems with the income data. As discussed in Chapter 3 above, the income data used in this study was the average income of tax paying inhabitants living in a municipality and is therefore aggregated. Furthermore, the minimum 
income for paying taxes only increased slightly over the study period (it did not increase with inflation). This means that today more people pay taxes. Finally, the number of part time jobs increased over the study period. In combination all these factors create a downward bias in income data over the study period.

The estimated parameters for quality adjusted car ownership cost are negative for all four study years, and increase over time starting at -0.06 (1970), -0.03 (1980), -0.02 (1990), and finally -0.01 (2000). This shows that the negative influence of car ownership cost decreases over time.

An important part of the research consisted of analyzing travel data based on origindestination spatial types. Sixteen different spatial relation types were defined and tested using four categories: major city (1), suburban (2), small freestanding city (3), and rural (4).

In Figure 7 the trend of the parameters for the spatial relation type (SRT) are shown. The parameters plotted in this figure illustrate the spatial dispersion and transport specific effects (e.g. transport system reliability, lack of parking space, parking charges, etc.), which were not captured in the other transport variables. Finally, it should be noted that the transport models used in this study contain the average daily workday traffic and therefore do not consider demand variations or possible overloading (congestion) during the day.

All parameters estimated in the spatial relation type analysis have the expected sign and are significant at the 95\%-level. The model shows that utility of private transport is negatively influenced by taking place in a major city, because the effect variables are in the private transport utility function; if the trip starts-in a major city (SRT 1x), ends-in a major city (SRT $\mathrm{x} 1$ ), or both starts and ends within a major city (SRT 11). On the other hand, for a trip starting and ending in a rural municipality the spatial pair's influence on mode choice for private transport is positive.

The parameter for the spatial relation type 11 (major city - major city) has the biggest negative value in 1970; and over time this negative utility increases. This holds as well for other SRTs where the destination of the work trip is in a major city (SRT 21, SRT 31 and SRT 41). The parameter SRT 22 (suburban-suburban) is positive, but decreases during the study period. The parameter for SRT 23, 24, 32 and 33 are positive and stay relatively constant. The parameters SRT 42, 43, 34 and 44 are also positive and over time their values increase significantly.

In general, the trend of the spatial type parameters shows a decreasing utility contribution of the spatial relation type in and around the major cities, in the rural parts of Switzerland however the commuters are very car oriented and this effect grows stronger over time.

Table 3 presents the direct and cross elasticity values of the mode choice model. The elasticity values show the relative change in demand for a relative change in an attribute. For example, a direct elasticity of the public transport travel time of -0.31 and a cross elasticity of 0.21 means that a $10 \%$ increase in public transport travel time reduces the demand for public transport by $3.1 \%$ and increases the demand for private transport by $2.1 \%$. 
It can be seen that the direct elasticity of public transport travel time stays in the same range from 1970 to 1990 and increases in the year 2000. The cross elasticity decreases over time. The elasticity values of number of transfers and headway are small and stay in a narrow band over time.

The direct elasticity of the public transport cost almost halves between 1970 and 2000 increasing from -0.18 to -0.10 . This indicates that public transport demand reacts less strongly to price increases in 1990 and 2000, than it did in 1970 and 1980. The cross elasticity decreased even more. The direct elasticity for private transport cost decreased during the study period from -0.15 (1970) to -0.05 (2000).

The direct elasticity of private transport travel time has a fairly constant value $(-0.20)$ over time. The cross elasticity increases from 0.36 (1970) to 0.53 (1980), 0.48 (1990), and to 0.63 (2000).

The impact of car ownership on the private transport demand increases by $50 \%$. The impact of car ownership is even stronger on the demand for public transport. Here the elasticity values start at -0.45 in 1970 decreases to -0.86 (1980), -1.21 (1990) and to -1.48 in 2000.

The income elasticity for private transport is positive in 1970 and 1980 and becomes negative in the latter years. As outlined above, these results are likely to be biased based on the data inconsistencies.

Figure 8 plots the value of travel time savings (VTTS) and the average hourly wage of Swiss industrial workers based on real (constant year 2000) values. The VTTS is calculated by dividing the travel time parameters with the travel cost parameter and measures the relative sensitivity to time and cost changes. The VTTS also helps to evaluate the willingness to pay for (i.e. accept increases in cost in return for) decreases in travel time. The industrial worker wage is probably upward biased in the early years because in the early 1970s Swiss industry was booming with an average unemployment rate of $0.3 \%$ causing significant upward pressure on wage rates.

The VTTS data show that employees traveling to work by automobile have a higher VTTS than those traveling by public transport. The ratio between VTTS for private transport and public transport has decreased over time. The biggest changes in the VTTS per decade occur for private transport during the 1970s, when the core motorway network was completed. For public transport the biggest change occurred a decade later, when the so called "Taktfahrplan" (headway based time table) was introduced.

The model specifications do not consider the change in time spent working from 1970 to 2000 in Switzerland. For example, in the mechanical industry the average working time fell from 44.7 hours per week in 1970 to 41.3 hours per week in 2000. The major decrease in the working time took place at the beginning of the 1990s. That may explain to some extent the huge increase of the VTTS, especially for the private transport, during the 1970s and 1980s. In the 1990s with relative constant amount of working time and low increase of the real wage, the estimated VTTS for private transport and public transport show a low increase. (11) also 
reported that VTTS for working trips increases faster than the real wage rate because of the reduction in working time.

The results for the year 2000 are, higher than the values from a VTTS-Study in the year 2003 using SP data in Switzerland (12).

Table 4 shows the results for the destination choice model. The parameter of the expected maximum utility (EMU) is positive in all years, which means that a good connection by the transport system to the destination favors the choice. The parameter stays around 2.90 from 1970 to 1990 . In 2000 the parameter, decreases to 2.47 , meaning that the weight of the transport system in the utility function is less important in 2000 than in earlier years.

The parameter for the log of the number of employees in the second sector (industry) starts with 0.34 in 1970, goes down to 0.18 in 1980 and 0.09 in 1990. Afterwards, in 2000 it turns negative with -0.05 . The attraction of jobs in the industrial sector decreases with a clear trend over time.

For the third sector (services), the parameter for the log of the number of employees develops in the opposite direction. The parameter starts at 0.76 (1970), jumps to 1.01 (1980), increases slightly to 1.04 (1990) and then to 1.08 in 2000. The attraction of jobs in the third sector increases strongly in the 1970s, afterwards the trend continues although less drastically.

Furthermore, the attraction of jobs in the third sector is stronger than in the second sector during every time period. It is also interesting to note that the destination choice parameters for the second and third sectors are different; this should be considered by the generation of OD-matrices for transport models.

Table 5 presents the results without the location type categorical variables of the interzonal trip generation model. It is assumed, that the models are identical scaled, and therefore the results are comparable.

The parameter of the expected maximum utility (EMU) from the destination choice stays positive over time, meaning the demand for the interzonal trips reacts positively to accessibility. The parameter decreases from 0.39 in 1970, to 0.34 in $1980,0.28$ in 1990 and finally to 0.28 in 2000 . These results can be interpreted that demand reacts with positive elasticity on accessibility (expected maximum utility), but also that the accessibility of a zone becomes less important for the generation of interzonal work trips over time. This finding can also be interpreted as the declining marginal utility of infrastructure projects over time.

The parameter for the ratio of jobs in the second sector to the number of working inhabitants is negative, implying that if more jobs are offered in the zone, there is a smaller likelihood that the economically active leave the zone for work. This parameter becomes more negative over time, from -0.07 in 1970 to -0.26 in 2000 . The parameter for the ratio of jobs in the third sector to the number of working inhabitants is also negative, but is lower during the whole study period and does not show a significant trend. 
The influence of the inhabitant's education level is examined with the next three parameters shown in Table 5. Unfortunately, the data set for 1970 is inconsistent with the following years because the 1970 census counted nurses and related education as having university degrees. The share of inhabitants with obligatory education or high school diploma have a negative sign in the utility function, except in the year 1990, which was an economical boom year and also the last year in the time period since 1950 with quasi non existing unemployment in Switzerland (unemployment rate in 1990 0.6\%). Inhabitants with high school diploma in the year 2000 also have a positive sign. The negative impact gets smaller over time, this implies that lower skilled workers are also more likely to leave there zone of residence for work. The parameter for the share of inhabitants with university degree is strongly positive except for 1970, when it is also not significant. From 1980 to 2000 the strong positive parameter means that inhabitants with university degrees and therefore with specialist educations are more likely to find suitable work outside their zone of residence.

The share of economically active women has a negative sign for all time periods, meaning that they have other obligations (mainly family) to fulfill and therefore are more bound to the origin zone. Interestingly, the parameter gets more negative between 1980 and 2000. The parameter for the log of the mean local income stays negative and does not show a trend.

\section{CONCLUSIONS}

The research study evaluates changes to travel behavior for commuter trips from 1970 to 2000. The study results provide several interesting insights into the impacts of long term changes to the transport system in Switzerland and socio-economic data on transport. Major changes occur in the mode choice for the attributes travel cost, quantity adjusted car ownership cost and car ownership per licensed driver. The study also shows that cost is a less significant factor in mode choice today than it was 20 or 30 years ago.

The influence of car ownership on the utility function has become stronger over time, and is the attribute for which the demand reacts most elastic. In general, it can be stated that employees who own automobiles will use them to get to work.

The influence of spatial geography is as expected. Trips within or to major cities and to a lesser extent within suburbs favor public transport; over time these effects become stronger. In rural areas, the use of private transport is positively influenced in the choice probability. This trend is also continuous over time.

In the destination choice model, the parameter of the expected maximum utility from the mode choice is positive, which means, a good connection by the transport system to the destination favors the choice probability, but the value decreases in the 1990s. The attraction of jobs in the third sector (services) is in every time period stronger than in the second sector (industry).

The interzonal trip generation models show a positive parameter of the expected maximum utility (accessibility) from the destination choice overtime, meaning that demand for the interzonal trips react positive elastic on accessibility. Furthermore, the parameter decreases 
during the 30-year study period, meaning that a zone's accessibility becomes less important for the generation of interzonal work trips.

\section{References}

1. Cervero, R. and M. Hansen (2002) Induced travel demand and induced road investment, Journal of Transport Economics and Policy, 36 (3) 469-490.

2. Hansen, M and Y. Huang (1997) Road supply and traffic in California urban areas, Transportation Research - A, 31 (3) 205-218.

3. Fröhlich, Ph. (2003) Induced Traffic: Review of the explanatory models, paper presented at the 3rd Swiss Transport Research Conference, Ascona, March 2003.

4. Louviere, J.J., D.A. Hensher and J. D. Swait (2000) Stated Choice Methods. Analysis and Applications, Cambridge University Press, Cambridge.

5. Kato, H., H. Ieda, Y. Kanayama and H.Honda (2001) Demand and Socio-economic Analyses of Direct-through Operation of Shinkansen Service to Existing Network, Journal of Eastern Asia Society for Transportation Studies, Vol.4, No.1, pp.93-105.

6. Greene, W.H. (2002) LIMDEP 8.0 -NLOGIT 3.0: Reference Guide, New York.

7. Fröhlich, Ph. and K.W. Axhausen (2004) Sensitivity of accessibility measurements to the underlying transport network model, Arbeitsberichte Verkehrs-und Raumplanung, 245, IVT, ETH Zürich, Zürich.

8. Beige, S. (2004) Ownership of mobility tools in Switzerland, paper presented at the 4th Swiss Transport Research Conference, Ascona, March 2004.

9. Abay, G. and E. Meier (2000) Preisentwicklung Personenverkehr 1995 - 2000, für das Bundesamt für Raumentwicklung (ARE), Zürich.

10. Frei, A. (2005) Was hätte man 1960 für einen Sharan bezahlt?, Master thesis, IVT, ETH Zürich.

11. Mackie, P.J., S. Jara-Diaz and A.S. Fowkes (2001) The value of travel time savings in evaluation, Transportation Research, 37 E (1) 91-106.

12. Axhausen, K.W., A. König, G. Abay, J.J. Bates and M. Bierlaire (2004) Swiss value of travel time savings, paper presented at the 2004 European Transport Conference, Strasbourg, October 2004. 


\section{List of Tables and Figures}

Table 1 Overview: Number of interzonal trips 1970-2000

Table 2 Parameters mode choice of commuters: Switzerland 1970-2000

Table 3 Elasticity values for commuter mode choice: Switzerland 1970-2000 (PuT: public transport; PrT: Private transport)

Table 4 Parameters destination choice of commuters: Switzerland 1970-2000

Table 5 Parameters interzonal trip generation of commuters: Switzerland 1970-2000

Figure 1 Model structure

Figure 2 Switzerland 1970-2000: Weighted travel speed for public transport (PuT) and private transport $(\operatorname{PrtT})$ commuters

Figure 3 Development of the parameters of spatial relation type: Switzerland 1970-2000

Figure 4 Commuter VTTS for PrT and PuT as well as wage per hour: Switzerland 19702000 
Table 6 Overview: Number of interzonal trips 1970-2000

\begin{tabular}{lrrrr}
\hline \multirow{2}{*}{ Number of trips } & \multirow{2}{*}{1970} & \multicolumn{2}{c}{1990} & \multicolumn{2}{l}{2000} \\
\hline Total inter zone trips & 946,229 & $1,252,184$ & $1,814,674$ & $2,023,295$ \\
Private Transport & 506,894 & 788,978 & $1,121,107$ & $1,339,685$ \\
Public Transport & 439,335 & 463,836 & 693,567 & 683,610 \\
Non-zero OD relations & 70,834 & 102,345 & 157,828 & 204,572 \\
\hline
\end{tabular}


Table 7 Parameters mode choice of commuters: Switzerland 1970-2000

\begin{tabular}{|c|c|c|c|c|}
\hline & 1970 & 1980 & 1990 & 2000 \\
\hline Number of observations & $54 ’ 374$ & $74^{\prime} 998$ & $117^{\prime} 292$ & $162^{\prime} 848$ \\
\hline Adj. $\rho^{2}$ & 0.065476 & 0.134087 & 0.155832 & 0.203994 \\
\hline Log Likelihood function & $-550^{\prime} 990.9$ & $-629^{\prime} 135.7$ & $-880 ' 691.6$ & $-960 ’ 201.4$ \\
\hline PuT travel time (h) & $-0.583 * *$ & $-0.485^{* *}$ & $-0.455^{* *}$ & $-0.628 * *$ \\
\hline Number of transfers (-) & $-0.104 * *$ & $-0.265 * *$ & $-0.265 * *$ & $-0.140 * *$ \\
\hline Headway (h) & $-0.103^{* *}$ & $-0.188^{* *}$ & $-0.194 * *$ & $-0.105^{* *}$ \\
\hline Travel cost (CHF) & $-0.164 * *$ & $-0.080 * *$ & $-0.035^{* *}$ & $-0.040 * *$ \\
\hline PrT travel time (h) & $-1.658^{* *}$ & $-1.838^{* *}$ & $-1.374 * *$ & $-1.593^{* *}$ \\
\hline Car per license holder & $1.581 * *$ & $1.714 * *$ & $2.392 * *$ & $2.860 * *$ \\
\hline $\begin{array}{l}\text { Income (CHF in real value of } \\
\text { the year 2000) }\end{array}$ & $0.207 * *$ & $0.073^{* *}$ & $-0.058 * *$ & $-0.192 * *$ \\
\hline $\begin{array}{l}\text { Quality adj. car ownership cost } \\
\text { (CHF in real value of the year } \\
\text { 2000) }\end{array}$ & $-0.063 * *$ & $-0.029 * *$ & $-0.023 * *$ & $-0.008^{* *}$ \\
\hline Spatial relation type 11 & $-1.135 * *$ & $-1.342 * *$ & $-1.403 * *$ & $-1.431 * *$ \\
\hline Spatial relation type 12 & $-0.089 * *$ & $-0.047 * *$ & $-0.051 * *$ & $-0.149 * *$ \\
\hline Spatial relation type 13 & $-0.181 * *$ & $-0.179 * *$ & $-0.118^{* *}$ & $-0.133 * *$ \\
\hline Spatial relation type 14 & $0.200^{* *}$ & $0.262 * *$ & $0.225^{* *}$ & $0.177 * *$ \\
\hline Spatial relation type 21 & $-0.230 * *$ & $-0.555^{* *}$ & $-0.801 * *$ & $-0.886 * *$ \\
\hline Spatial relation type 22 & $0.545^{* *}$ & $0.495^{* *}$ & $0.391 * *$ & $0.323 * *$ \\
\hline Spatial relation type 23 & $0.151 * *$ & $0.118^{* *}$ & $0.251 * *$ & $0.295 * *$ \\
\hline Spatial relation type 24 & $0.696^{* *}$ & $0.610 * *$ & $0.654 * *$ & $0.615^{* *}$ \\
\hline Spatial relation type 31 & $-0.739 * *$ & $-0.796 * *$ & $-0.951 * *$ & $-1.007^{* *}$ \\
\hline Spatial relation type 32 & $0.078 * *$ & $0.177 * *$ & $0.316^{* *}$ & $0.341 * *$ \\
\hline Spatial relation type 33 & $0.177 * *$ & $0.137 * *$ & $0.148^{* *}$ & $0.236 * *$ \\
\hline Spatial relation type 34 & $0.237^{* *}$ & $0.419 * *$ & $0.630 * *$ & $0.649 * *$ \\
\hline Spatial relation type 41 & $-0.428 * *$ & $-0.424 * *$ & $-0.734 * *$ & $-0.785 * *$ \\
\hline Spatial relation type 42 & $0.239 * *$ & $0.404 * *$ & $0.467 * *$ & $0.535 * *$ \\
\hline Spatial relation type 43 & $0.034 * *$ & $0.161 * *$ & $0.242 * *$ & $0.388 * *$ \\
\hline Spatial relation type $44^{1}$ & 0.445 & 0.560 & 0.734 & 0.832 \\
\hline
\end{tabular}


Table 8 Elasticity values for commuter mode choice: Switzerland 1970-2000 (PuT: public transport; PrT: Private transport)

\begin{tabular}{lccccccccc}
\hline & \multicolumn{1}{c}{1970} & \multicolumn{2}{c}{1980} & \multicolumn{2}{c}{1990} & \multicolumn{2}{c}{2000} \\
\cline { 2 - 10 } & PrT & PuT & PrT & PuT & PrT & PuT & PrT & PuT \\
\hline PuT travel time & 0.209 & -0.313 & 0.129 & -0.347 & 0.135 & -0.362 & 0.171 & -0.560 \\
Number of transfers & 0.020 & -0.029 & 0.034 & -0.091 & 0.045 & -0.120 & 0.024 & -0.077 \\
Headway & 0.061 & -0.091 & 0.064 & -0.172 & 0.045 & -0.121 & 0.023 & -0.076 \\
PuT cost & 0.123 & -0.184 & 0.049 & -0.131 & 0.028 & -0.075 & 0.029 & -0.095 \\
PrT cost & -0.151 & 0.226 & -0.063 & 0.169 & -0.036 & 0.096 & -0.045 & 0.146 \\
PrT travel time & -0.239 & 0.358 & -0.196 & 0.527 & -0.178 & 0.480 & -0.192 & 0.629 \\
Car ownership rate & 0.300 & -0.450 & 0.319 & -0.859 & 0.448 & -1.206 & 0.452 & -1.477 \\
Income & 0.433 & -0.648 & 0.102 & -0.274 & -0.080 & 0.216 & -0.222 & 0.726 \\
\hline
\end{tabular}


Table 9 Parameters destination choice of commuters: Switzerland 1970-2000

\begin{tabular}{lrrrrr}
\hline & 1970 & & 1980 & & \multicolumn{2}{c}{2000} \\
\hline Number of observations & $2^{\prime} 454$ & $2^{\prime} 181$ & $2^{\prime} 110$ & $2^{\prime} 171$ \\
Adj. $\rho^{2}$ & 0.328 & 0.297 & 0.247 & 0.230 \\
& & & & \\
EMU mode choice & $2.884^{* *}$ & $2.791^{* *}$ & $2.984^{* *}$ & $2.465^{* *}$ \\
Log employees 2nd sector & $0.336^{* *}$ & $0.175^{* *}$ & $0.088^{* *}$ & $-0.048^{* *}$ \\
Log employees 3rd sector & $0.762^{* *}$ & $1.011^{* *}$ & $1.044^{* *}$ & $1.083^{* *}$ \\
\hline Note: $(*) t$ test significant on $95 \%$-level $(\alpha<0.05) ;(* *) t$ test significant on $99 \%$-level $(\alpha<0.01) ;$ &
\end{tabular}

Note: $(*) \mathrm{t}$ test significant on $95 \%$-level $(\alpha<0.05) ;(* *) \mathrm{t}$ test significant on $99 \%$-level $(\alpha<0.01)$; 
Table 10 Parameters interzonal trip generation of commuters: Switzerland 1970-2000

\begin{tabular}{|c|c|c|c|c|}
\hline & 1970 & 1980 & 1990 & 2000 \\
\hline Number of observations & $2 ’ 452$ & 2'178 & 2'110 & 2'171 \\
\hline Pearson Goodness-of-Fit & significant & significant & significant & significant \\
\hline EMU Destination choice & $0.393 * *$ & $0.340 * *$ & $0.279 * *$ & $0.275^{* *}$ \\
\hline Employees 2nd Sector to active population & $-0.069 * *$ & $-0.044 * *$ & $-0.247 * *$ & $-0.258 * *$ \\
\hline Employees 3rd Sector to active population & $-0.055^{* *}$ & $-0.034 * *$ & $-0.020 * *$ & $-0.031 * *$ \\
\hline Share of inhabitants with obligatory education & $-0.805^{* *}$ & $-0.556^{* *}$ & $1.106^{* *}$ & -0.005 \\
\hline Share of inhabitants with high school diploma & $-0.350 * *$ & $-0.652 * *$ & $0.291 * *$ & $-0.619 * *$ \\
\hline Share of inhabitants with university education & -0.034 & $3.389 * *$ & $5.740 * *$ & $3.341 * *$ \\
\hline Share of employed women of active population & $-2.127 * *$ & $-1.121 * *$ & $-1.305^{* *}$ & $-2.248 * *$ \\
\hline Log Mean local income (CHF in real value year 2000) & $-0.657 * *$ & $-0.866^{* *}$ & $-0.868 * *$ & $-0.452 * *$ \\
\hline Alternative specific constant & $0.443 * *$ & $0.945^{* *}$ & $0.845^{* *}$ & $-0.421 * *$ \\
\hline
\end{tabular}


Figure 5 Model structure

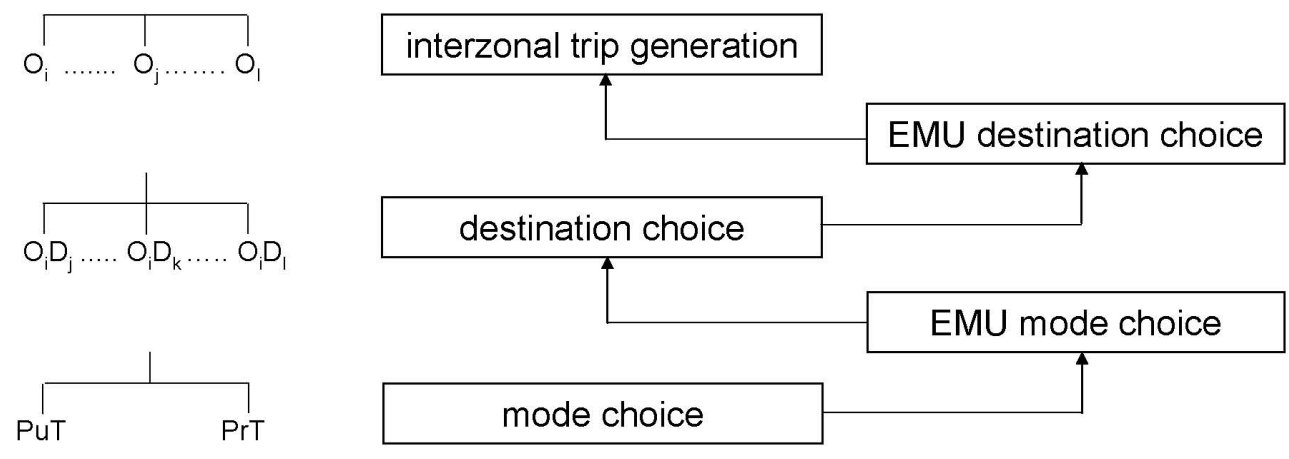

Note: EMU means expected maximum utility 
Figure 6 Switzerland 1970-2000: Weighted travel speed for public transport (PuT) and private transport $(\operatorname{PrtT})$ commuters

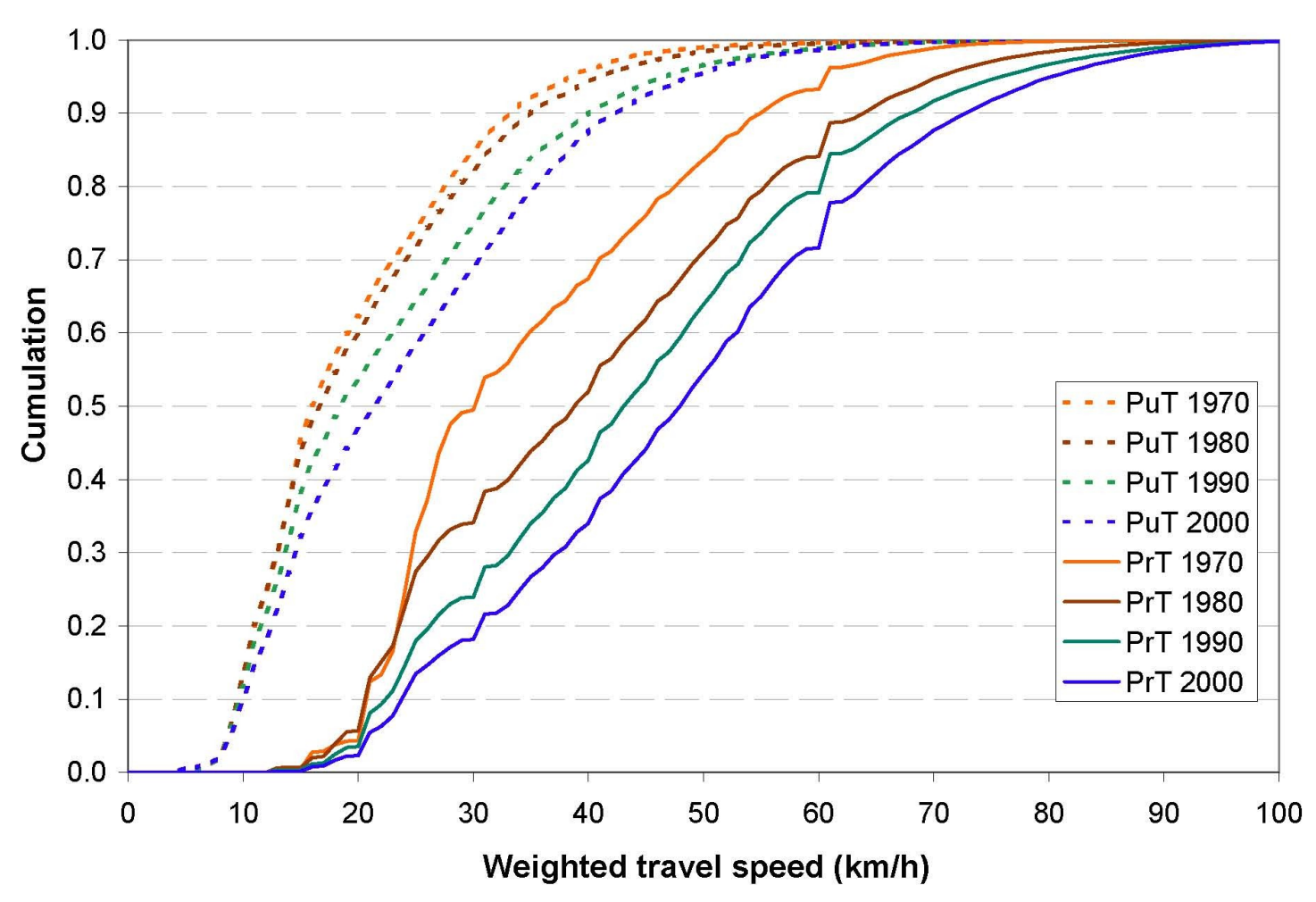


Figure 7 Development of the parameters of spatial relation type: Switzerland 1970-2000

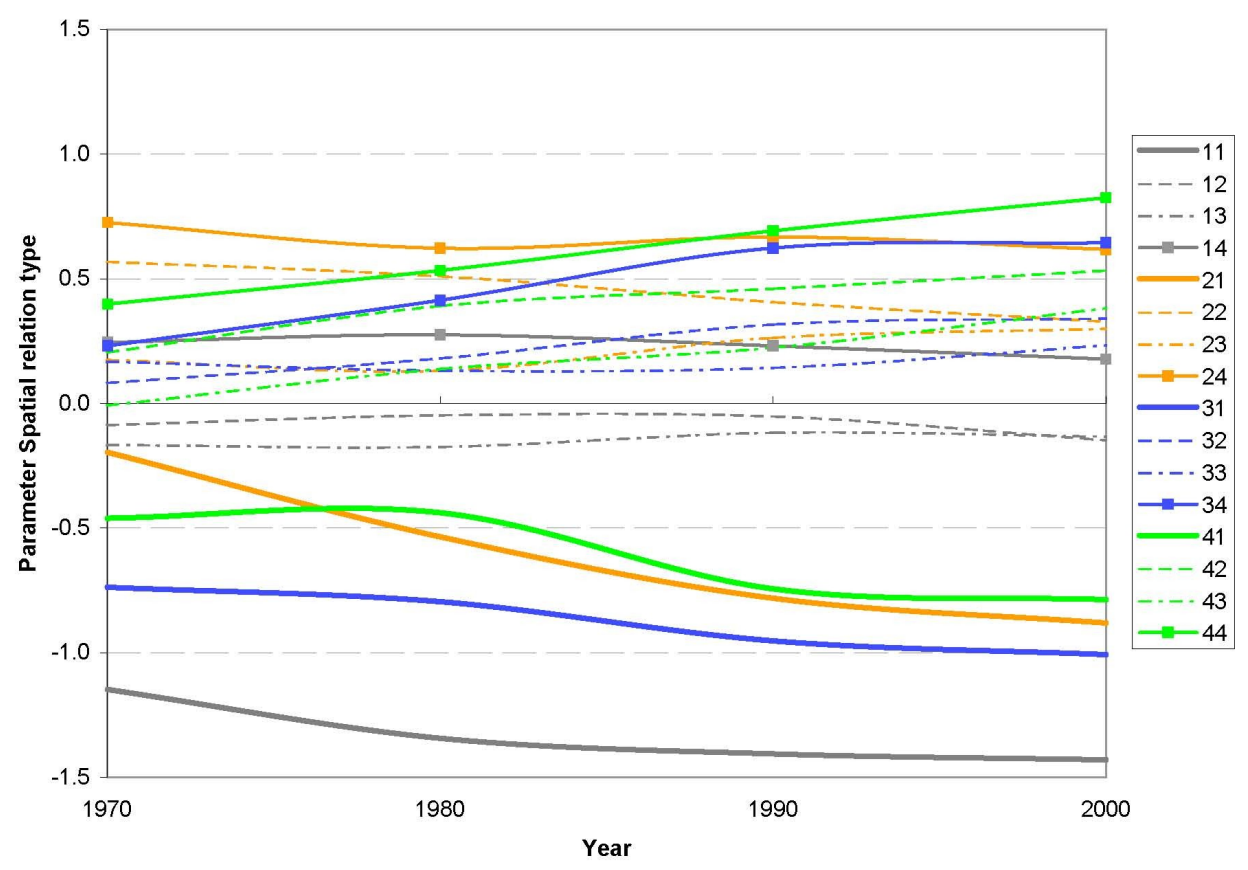

To/from: 1 = major city; 2 = suburban; 3 = small freestanding city; $4=$ rural

Figure 8 Commuter VTTS for PrT and PuT as well as wage per hour: Switzerland 1970-2000 


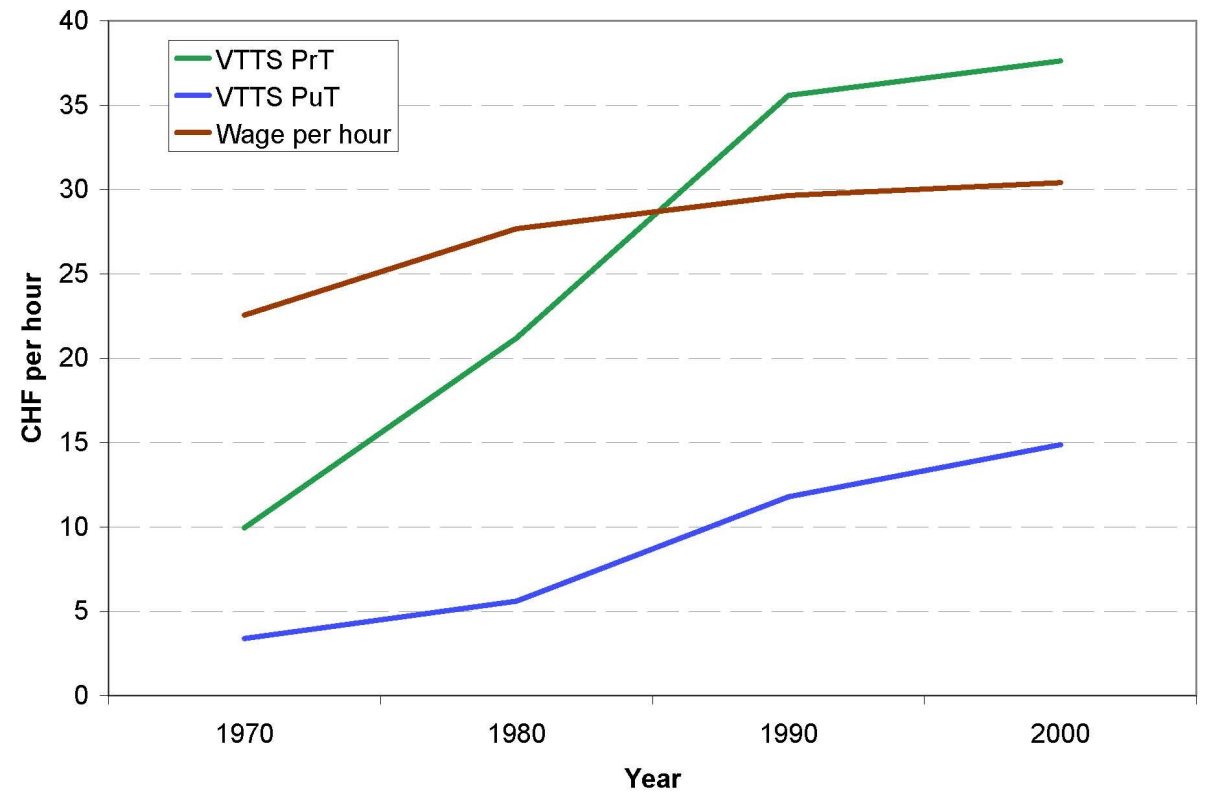

Note: in real value for the year 2000 